Article

\title{
Gas-to-Particle Conversion in Surface Discharge Nonthermal Plasmas and Its Implications for Atmospheric Chemistry
}

\section{Hyun-Ha Kim * and Atsushi Ogata}

National Institute of Advanced Industrial Science and Technology (AIST), AIST Tsukuba West, 16-1 Onogawa, Tsukuba, Ibaraki 305-8569, Japan; E-Mail: atsushi-ogata@aist.go.jp

* Author to whom correspondence should be addressed; E-Mail: hyun-ha.kim@aist.go.jp.

Received: 6 January 2011; in revised form: 21 February 2011 / Accepted: 4 March 2011 /

Published: 7 March 2011

\begin{abstract}
This paper presents some experimental data on gas-to-particle conversion of benzene using nonthermal plasma (NTP) technology and discusses the possibility of its technical application in atmospheric chemistry. Aerosol measurement using a differential mobility analyzer (DMA) revealed that the parts of benzene molecules were converted into a nanometer-sized aerosol. Aerosol formation was found to be highly related with the missing part in carbon balance. Scanning electron microscopy analysis showed that the aerosols formed in synthetic humid air are the collection of nanoparticles. The carbonyl band $(\mathrm{C}=\mathrm{O})$ was found to be an important chemical constituent in the aerosol. The potential of the NTP as an accelerated test tool in studying secondary organic aerosol (SOA) formation from VOCs will be also addressed.
\end{abstract}

Keywords: nonthermal plasma; aerosol formation; secondary organic aerosol (SOA); volatile organic compound (VOC)

\section{Introduction}

The emission of volatile organic compounds (VOCs) into open air is of great importance in terms of photochemical smog and secondary organic aerosols (SOA). These two air pollution events occur at the same time, mostly in urban areas. Aerosol formation in the troposphere in particular leads to degraded visibility and has direct health effects on human beings. VOC emission regulations in many countries are aimed basically at the reduction of these two problems. VOC-related chemistry and its potential for SOA formation have been the subject of intensive studies in the past three decades [1]. 
A nonthermal plasma (NTP) is a partially ionized gas which can induce various chemical reactions, even at room temperature and atmospheric pressure. In contrast to the thermal plasma where all the components are at thermal equilibrium (usually around 10,000 K), an NTP is characterized by the different energy states between electrons, ions and neutral molecules. Because of their small mass electrons can be easily accelerated under the influence of electric fields and attain kinetic energies of up to $20 \mathrm{eV}$. These energetic electrons ionize and dissociate background molecules, resulting in the formation of highly reactive chemical species (radicals, ions, excited molecules and ozone). Ozone generation is one good example of a nonthermal plasma chemical reaction, which is used extensively in various industries [2,3]. NTP has also been considered as a control technology for various air pollutants such as SOx, NOx and VOCs [4]. One of important issues in plasma technology is the formation of unwanted byproducts including aerosols. Most recent work on VOC removal look at the combination of NTP with a catalyst due mostly to the concerns about energy efficiency and byproducts $[5,6]$. The plasma chemical reactions are based on the gas-phase radical reactions involving chemically active species (CAS) such as atomic oxygen, hydroxyl radicals, peroxy radicals and ozone, which is quite similar to atmospheric chemistry. The extensive database on chemical reactions involving CAS has also been used in modeling plasma chemical reactions. Table 1 compares the major chemical components in the NTP process and the atmospheric chemistry. Although a chamber test provides reliable data on the photochemical reactions under controlled reaction conditions, which are similar to those in photochemical smog episodes, the major drawbacks are the large facility and long reaction time [7,8]. On the other hand, gas-to-particle conversion in an NTP takes place on a short time scale due to the high concentrations of chemically reactive species. The concentrations of these species are 3-8 orders of magnitude larger than those observed in atmospheric chemistry. It is also of interesting, from the viewpoint of practical applications of NTP as a tool for atmospheric chemistry, to study the formation of SOA, i.e.,

(1) one can easily control the reaction rate by adjusting the energy input to the reactor,

(2) it requires only a simple and compact reaction chamber, and

(3) it can be easily prepared and coupled with various on-line measurement instruments.

Table 1. Typical parameters in atmospheric chemistry and plasma chemistry (in air).

\begin{tabular}{ccc}
\hline Parameters & Atmospheric Chemistry & Plasma Chemistry \\
\hline Temperature & $273 \sim 293 \mathrm{~K}$ & $<373 \mathrm{~K}$ \\
OH radicals & $\sim 10^{6} \mathrm{~cm}^{-3}$ & $\sim 10^{15} \mathrm{~cm}^{-3}$ \\
$\mathrm{O}_{3}$ & $\sim 10^{-1} \mathrm{ppm}^{-2}$ & $\sim 10^{3} \mathrm{ppm}^{-2}$ \\
UV intensity & $\sim 10^{2} \mathrm{mWcm}^{-2}$ & $\sim \mu \mathrm{Wcm}^{-2}$ \\
NOx & $<\mathrm{ppm}$ & $\sim 10^{2} \mathrm{ppm}$ \\
Reactant & $\sim \mathrm{ppb}$ & $\sim \mathrm{ppm}$ \\
\hline
\end{tabular}

Gas-to-particle conversion in plasma chemical reactions has been observed by the formation solid products on the surface, which is referred to as polymerization $[9,10]$. In recent years, Anderson et al. observed polymer deposition in the decomposition of 5,370 ppm styrene using a silent discharge plasma reactor in an $\mathrm{Ar} / \mathrm{O}_{2}$ mixture [11]. Polymerization of phenol vapor was studied in a dielectric-barrier discharge plasma [12]. The polymerization rate was found to be dependent not only 
on the discharge power but also the properties of the surface. Machala et al. observed the deposition of solid product from a pilot-scale test on VOC mixtures (mostly cyclohexanone) [13]. They measured the solid products using DRIFT and high-precision liquid chromatography (HPLC) and found amino acids as the main component of the solid products. Nolan and his colleagues directly measured nanometer-sized aerosols in negative point corona discharges [14,15]. Later, Borra et al. studied aerosol formation in point-to-plane DC corona for both polarities [16], and various types of discharges (such as streamers, spark, and dielectric barrier discharge) as well [17]. Formation of submicron-sized aerosols and their chemical composition have been confirmed using FTIR and SEM in the X-ray irradiation of benzene or acetylene (below about 1,000 ppm) in air [18]. Despite big advances in the understanding of nonthermal plasma chemistry over the past two decades, the mechanism for the aerosol formation remains elusive. A practical viewpoint, i.e., the consideration of aerosols as unwanted byproducts, has also hindered studies focusing on the fundamental processes of gas-to-particle conversion.

This paper presents experimental results on the aerosol formation from benzene in nonthermal plasma-induced chemical reactions. The size distribution and number concentration were evaluated using a differential mobility analyzer (DMA) and a Faraday cup (FC). The morphology and the chemical composition of the aerosol were measured with scanning electron microscopy (SEM) and a diffuse reflectance infrared Fourier transform (DRIFT) spectrometer, respectively. The similarity of NTP with atmospheric chemistry with regards to aerosol formation and the application of NTP as a tool for the accelerated testing of VOC-to-particle conversion will also be discussed.

\section{Experimental}

Figure 1 shows the experimental setup (a) and the DMA (differential mobility analyzer; Wyckoff Co., Ltd.) equipped with a Faraday cup (FC) for the aerosol measurement. Since the size range was found to below $100 \mathrm{~nm}$ in the previous study [19], the DMA was optimized to measure aerosols smaller than $100 \mathrm{~nm}$. The experimental setup consisted of the plasma reactor, power supply, oscilloscope, and gas cylinders. A cylindrical surface discharge plasma reactor was used in this study. The inner diameter and effective length of the quartz tube were $15 \mathrm{~mm}$ and $200 \mathrm{~mm}$, respectively. A coil-type electrode $(0.45 \mathrm{~mm}$ diameter) was set at the inner surface of the quartz tube, which served as a high-voltage electrode. Silver paste was painted on the outer surface of the reactor as a ground electrode. The plasma reactor was energized with AC high-voltage. The input signal from the function generator (Tektronix, AFG 310) was amplified 2000-fold by a Trek 20/20B amplifier, and then applied to the plasma reactor. The charge $\mathrm{Q}$ was measured with a capacitor of $1 \mu \mathrm{F}$ connected in series to the grounded line of the plasma reactors. The discharge power (W) dissipated in the plasma reactor was measured by V-Q Lissajous figure method. Specific input energy (SIE), discharge power (W) transferred to the unit gas flow rate (liters per min; LPM), is calculated from the following equation:

$$
\text { Specific input energy }(\mathrm{J} / \mathrm{L})=\frac{\text { discharge power }(\text { watt })}{\text { gas flow rate }(\mathrm{L} / \mathrm{min})} \times 60
$$

The units of $\mathrm{J} / \mathrm{L}$ can be converted into $\mathrm{Wh} / \mathrm{Nm}^{3}$ by multiplying by a factor of 3.6. Applied voltage and discharge current were measured using a digital oscilloscope (Tektronix, TDS 3032) connected 
with a high voltage probe (Tektronix, P6015A) and an current probe (Pearson Electronics Inc., Model 2877), respectively.

Figure 1. Schematic diagram of the experimental setup (a) and differential mobility analyzer (DMA) and Faraday cup (FC) for aerosol measurement (b).

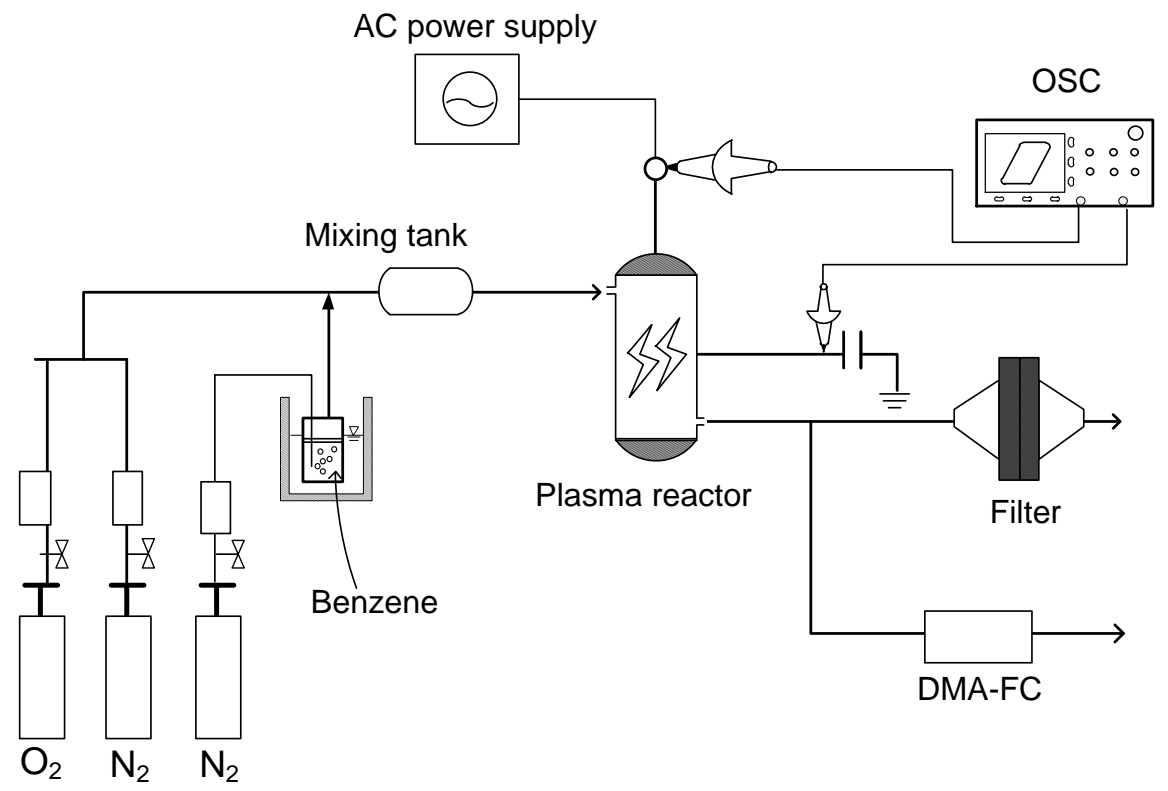

(a) Setup

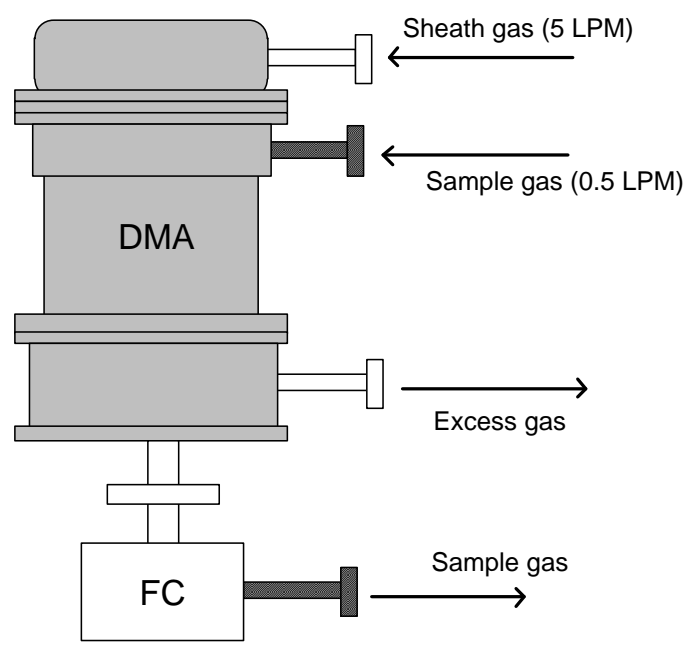

(b) DMA-FC

The shape of the aerosol was measured using field-emission scanning electron microscopy (FE-SEM; TOPCON Co. Model DS-720). The discharge with $\mathrm{N}_{2}$ gas became unstable with time as the deposition of solid products occurred on the inner surface of the plasma reactor. Considering this property, aerosol sampling time was varied from about $30 \mathrm{~min}$ for $\mathrm{N}_{2}$ to about $120 \mathrm{~min}$ for air. The chemical structure of the aerosol was measured using a Diffuse Reflectance Infrared Fourier Transform (DRIFT) spectrometer (Perkin Elmer, Spectrum One). The diffractive reflectance cell was purged with pure nitrogen (2 LPM) during the measurements. The spectrum data were taken by averaging 60 scans with the resolution of $2 \mathrm{~cm}^{-1}$. Background spectrum was measured using a clean filter instead of normal method using KBr. A DMA (differential mobility analyzer; Wyckoff Co., Ltd.) 
equipped with a Faraday cup (FC) was used to measure the size distribution and the number concentration of aerosols. The DMA used in this study can measure aerosol size from $1 \mathrm{~nm}$ to $90 \mathrm{~nm}$, depending on the flow rate and applied voltage. To reduce aerosol loss during the transportation, Tygon tube or stainless steel was used as tubing. The current in the FC was measured with a femto-ampere electrometer. The sample gas to the DMA was injected at 0.5 LPM while the sheath gas was at 5 LPM. The distance between the outlet of the plasma reactor and the inlet of the DMA was about $20 \mathrm{~cm}$.

All experiments have been done at atmospheric pressure and room temperature. Gas flow rate was set at $2 \mathrm{LPM}$ under standard condition $(273 \mathrm{~K}, 0.1 \mathrm{MPa})$ unless otherwise noted. This corresponds to a gas residence time of $1.06 \mathrm{~s}$. Synthetic air or nitrogen were adjusted using mass flow controllers and gas cylinders, which also ensure conditions free from background aerosols. The purities of nitrogen and oxygen were $99.999 \%$ and $99.9 \%$, respectively. A bottle containing deionized water was immersed in a water bath maintained at $25{ }^{\circ} \mathrm{C}$ to sustain a constant water content of $0.5 \%$. Benzene concentration was adjusted by the same bubbling method and the resulting benzene-laden $\mathrm{N}_{2}$ gas was mixed with the main $\mathrm{O}_{2} / \mathrm{N}_{2}$ gas stream. The water vapor content was measured with a dew point hygrometer (General Eastern, Hygro-M4). Benzene concentration was measured with on-line FTIR equipped with a long-path gas cell $(6.4 \mathrm{~m})$. A PTFE membrane filter $(0.1 \mu \mathrm{m}$; ADVANTEC Inc.) was used in sampling aerosols for the DRIFT spectrometer. Qualitative filter paper (No. 2, ADVANTEC Inc.) was used in sampling aerosols for the FE-SEM measurement.

\section{Results and Discussion}

\subsection{Chemical Conversion of Benzene}

Gas-phase benzene was fed into the plasma reactor and its conversion rate and byproducts were measured using the on-line FTIR spectrometer. Figure 2 shows the conversion of benzene (a) and the carbon balance as a function of SIE (b). Gas-phase products determined from the FTIR spectrometer were $\mathrm{CO}_{2}, \mathrm{CO}$ and $\mathrm{HCOOH}$ (formic acid). Based on the quantitative FTIR measurement, carbon balance was calculated from the following equation:

$$
\text { Carbon balance }(\%)=\frac{[\mathrm{CO}]+\left[\mathrm{CO}_{2}\right]+[\mathrm{HCOOH}]}{6\left(\left[\mathrm{C}_{6} \mathrm{H}_{6}\right]_{0}-\left[\mathrm{C}_{6} \mathrm{H}_{6}\right]\right)} \times 100
$$

where $\left[\mathrm{C}_{6} \mathrm{H}_{6}\right]_{0}$ and $\left[\mathrm{C}_{6} \mathrm{H}_{6}\right]$ indicate the inlet and the outlet concentrations of benzene, respectively. The concentration of benzene showed an exponential decay with SIE. The removal efficiency reached 50\% at about $360 \mathrm{~J} / \mathrm{L}$. On the other hand, the carbon balance was about $60 \%$ at SIE below $100 \mathrm{~J} / \mathrm{L}$, and monotonically increased with further increases of SIE.

The missing parts in carbon balance are often found as solid products (including aerosols) on the reactor wall or on the tubing. Figure 3 shows the size distribution of the aerosol according to the energy input to the plasma reactor. It should be noted that aerosol formation did not occur in the absence of benzene in this study. The formation of solid products in benzene- $\mathrm{N}_{2}$ mixtures was so rapid that the stable operation of the reaction was hampered with time. For this reason, aerosol measurements with DMA-FC were only done for air mixtures. Aerosol formation was detected even at low SIE of $7.8 \mathrm{~J} / \mathrm{L}$. The peak size and number concentration kept increasing up to $47.2 \mathrm{~J} / \mathrm{L}$, and 
reached $25 \mathrm{~nm}$ and $1.4 \times 10^{7}$ particles $/ \mathrm{cm}^{3}$, respectively. When the SIE was increased to $81.1 \mathrm{~J} / \mathrm{L}$ the number concentration decreased by about $30 \%$ without changing the size distribution. These growth and decay characteristics of aerosols with SIE can be explained by the branching of chemical reaction. At low SIE range below about $50 \mathrm{~J} / \mathrm{L}$, formation and growth of aerosol are occurring dominantly. On the other hand, the produced aerosols may further undergo oxidation that dominates at SIE values higher than about $50 \mathrm{~J} / \mathrm{L}$. The unimodal distribution changed to a bimodal distribution at $162 \mathrm{~J} / \mathrm{L}$. Aerosols completely disappeared at $357 \mathrm{~J} / \mathrm{L}$, which is consistent with the carbon balance data in Figure 2(b). This observation also indicates that the aerosols are composed mostly of organic compounds.

Figrue 2. Benzene removal in the surface discharge plasma reactor; (a) removal efficiency, (b) carbon balance.
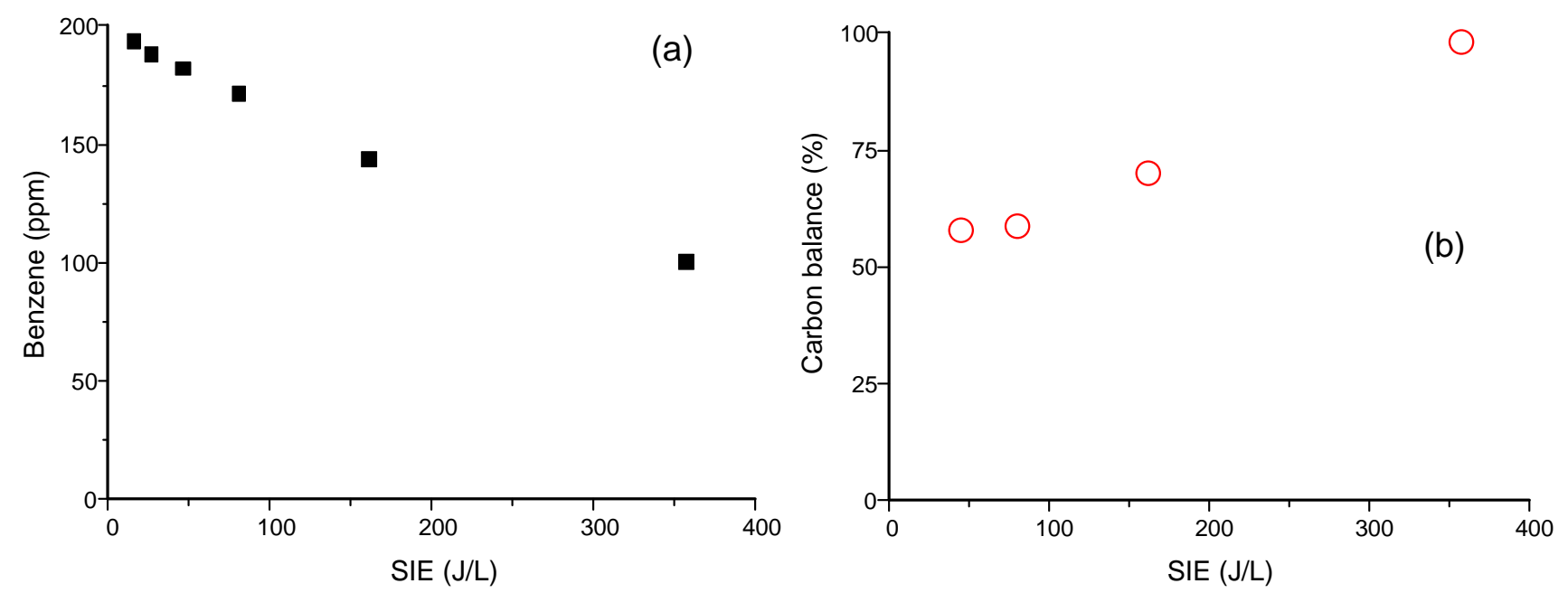

Figure 3. Size distribution of aerosol according to specific input energy to the plasma reactor. (204 ppm benzene in humid air).

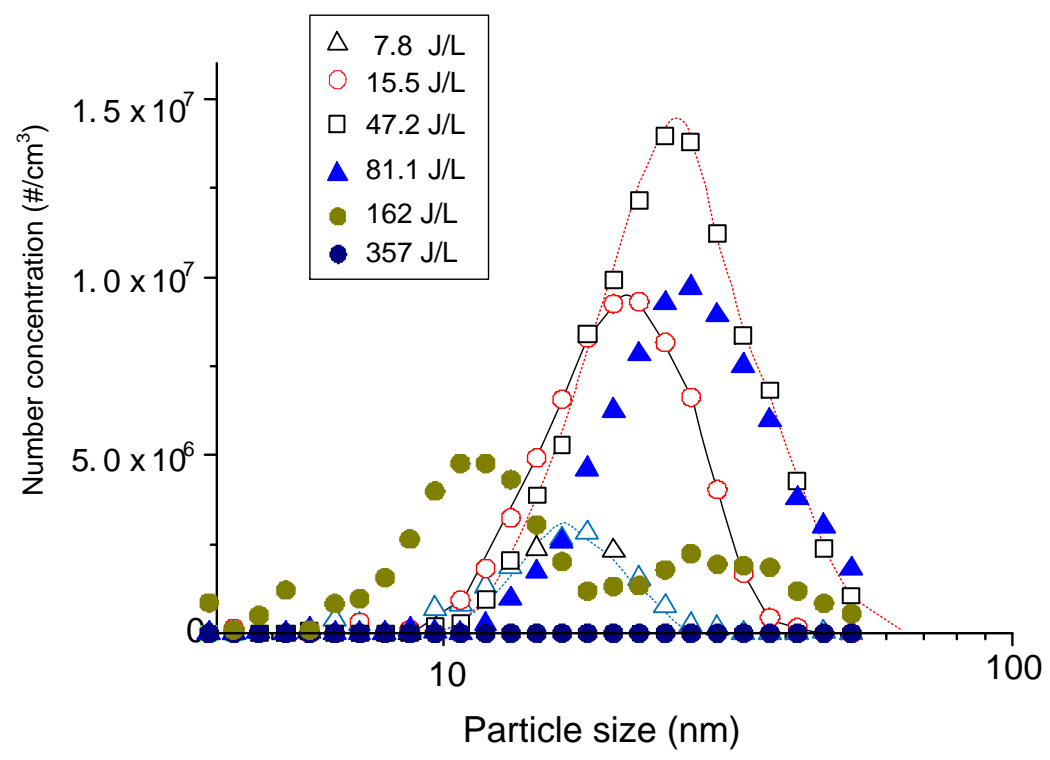


Figure 4 shows the influence of benzene concentration on the number concentration of the aerosol. The SIE was fixed at around $50 \mathrm{~J} / \mathrm{L}$ and the size distribution and the number concentration were measured with the DMA-FC. As expected, number concentration of aerosol was largely influenced by the benzene concentration. When the benzene concentration was increased from $50 \mathrm{ppm}$ to $200 \mathrm{ppm}$, the number concentration increased by a factor of 10 . At the same time, peak sizes were also increased with the inlet concentration of benzene. In our previous works using a scanning mobility particle sizer (SMPS, TSI), surface discharge produced aerosols with a lower number concentration of $5.9 \times 10^{4}$ particles $/ \mathrm{cm}^{3}$ with a larger peak size of $39 \mathrm{~nm}$ [19]. Besides the different measuring instrument, the long distance $(3 \mathrm{~m}$ ) before entering the SMPS is believed to be the main reason for the difference in size distribution. Coagulation is a typical characteristic of aerosols, especially in the nanometer-sized range, resulting in the growth in size. The short distance $(20 \mathrm{~cm})$ between the plasma reactor and the DMA provides information about aerosols much closer to those in the plasma reactor. Since the gas mixtures fed to the plasma reactor were free from background aerosols or $\mathrm{NH}_{3}$, ions generated in the plasma reactor are expected to play an important role in this process. Ion-induced nucleation is well-known to play an important role in the gas-to-particle process in a plasma environment [20]. If we assume that the main chemical reactions occur during the discharge period, the density of charge carrier $\left(\mathrm{N}_{\mathrm{e}}\right)$ during the reactions can be calculated from the measured discharge current density, $\mathrm{J}\left(\mathrm{A} / \mathrm{cm}^{2}\right)[21,22]$ :

$$
\mathrm{J}=e \mathrm{~N}_{\mathrm{e}} v
$$

where $e$ and $v$ are the elementary charge $\left(1.6 \times 10^{-19} \mathrm{C}\right)$ and drift velocity, respectively. For the typical conditions in this study $(\mathrm{E}=10 \mathrm{kV} / \mathrm{cm}$, average discharge current $=5 \mathrm{~mA}$, reduced electric field $(\mathrm{E} / \mathrm{N})=80 \mathrm{Td})$ the $\mathrm{N}_{\mathrm{e}}$ in the plasma reactor was calculated to about $\sim 10^{8} / \mathrm{cm}^{3}$. Since the diameter of microdischarge (streamer) is about $100 \mu \mathrm{m}$, the local ion density in the reaction zone is expected to reach up to $\sim 10^{12} / \mathrm{cm}^{3}$.

Figure 4. Influence of benzene concentration on the number concentration of aerosols (humid air). The figures in parentheses indicate the peak size.

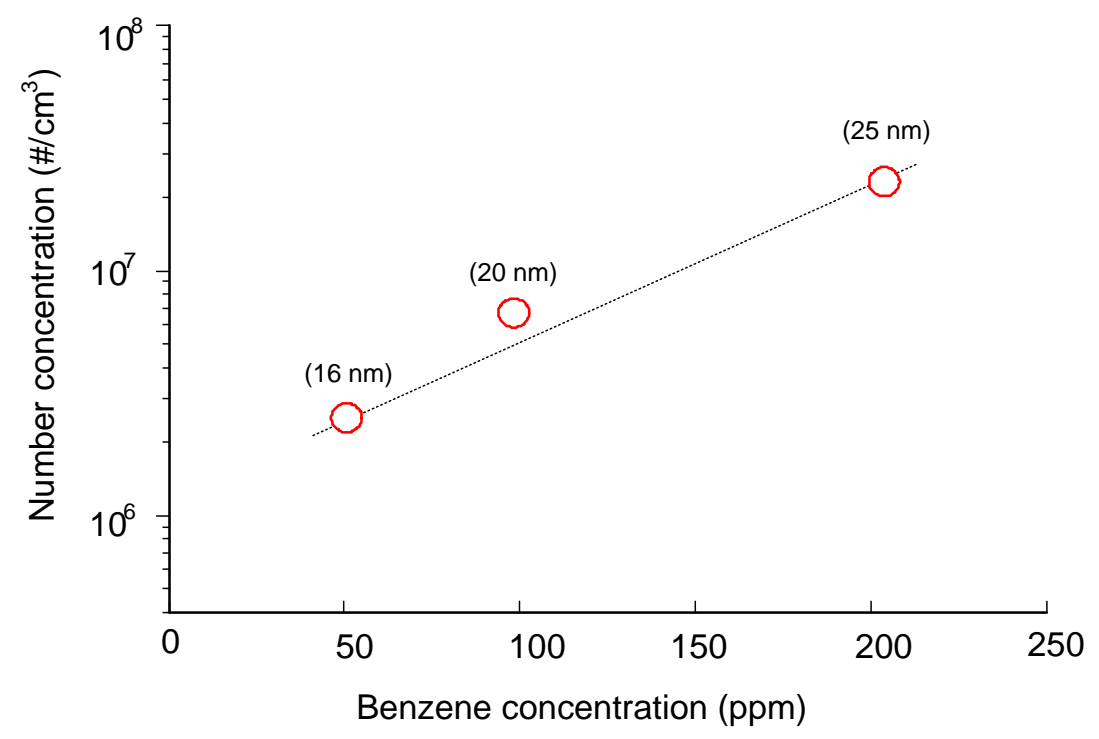




\subsection{Aerosol Analysis}

Figure 5 shows FE-SEM photos of the aerosol collected downstream of the plasma reactor. In the case of air mixtures, the size of aerosols (a) collected on the filter was in the 0.5-2.0 $\mu \mathrm{m}$ range. The FE-SEM photo with further magnification, (b) $\times 20,000$, clearly indicated that the each particle is a collection of nanometer-sized aerosols, which is consistent with the DMA measurement. Under nitrogen conditions, deposition of solid products with dark-brown colors can be observed near the outlet of plasma reactor, even with the naked eye. The FE-SEM photos indicated that the aerosols formed in a $\mathrm{N}_{2}$ environment had smooth surfaces and irregular size $(1-5 \mu \mathrm{m})$. In an early review by Fomin it was indicated that the reaction of benzene with active nitrogen produced nitrogen-containing polymers [23].

Figure 5. FE-SEM photos of the aerosol; (a) and (b) humid air, (c) and (d) humid $\mathrm{N}_{2}$. Benzene concentration was about 250 ppmv.
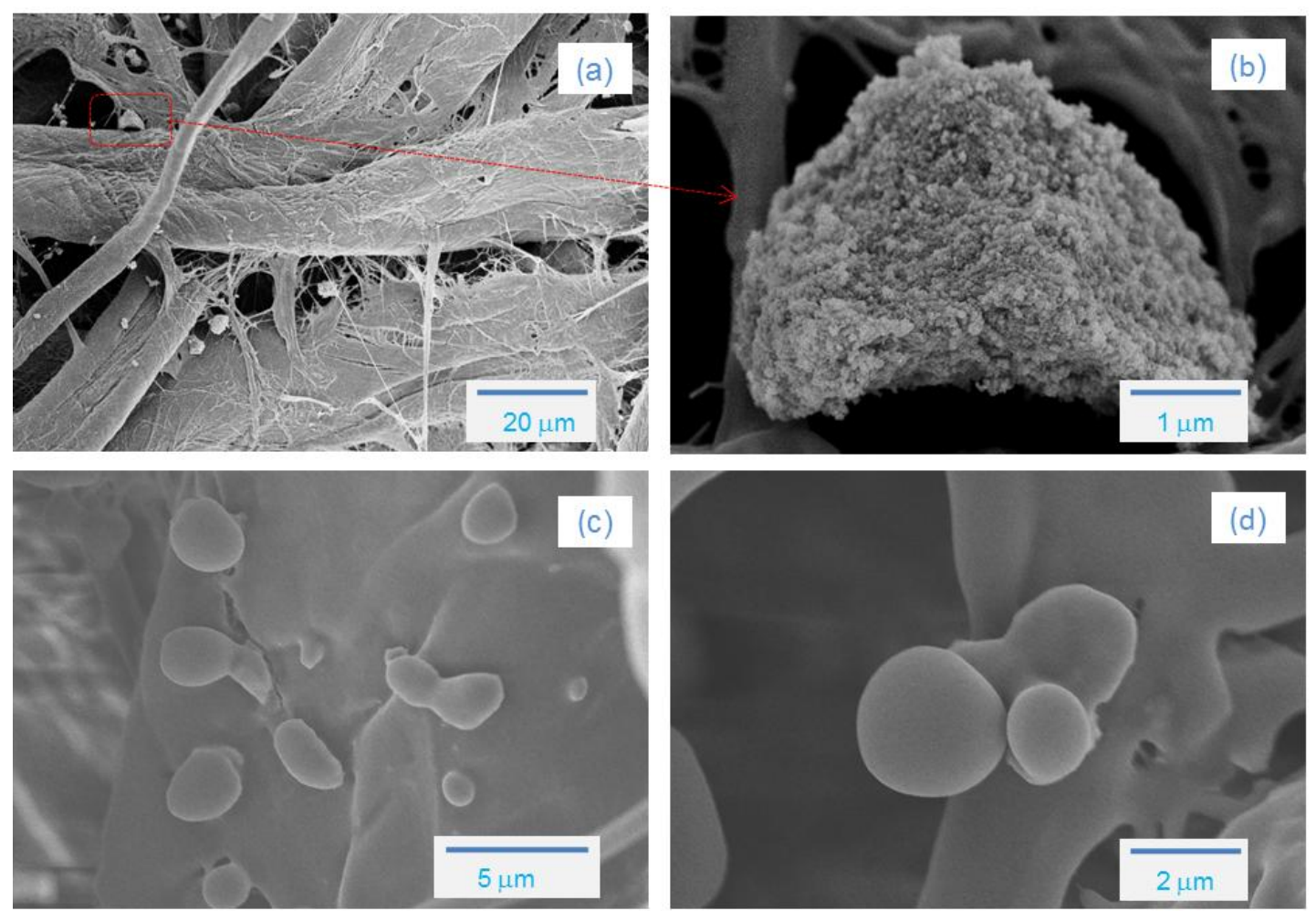

The chemical composition of the aerosol was measured with the DRIFT spectrometer, and the data are shown in Figure 6. To avoid water adsorption on the filter, a PTFE membrane filter used in aerosol sampling for the DRIFT measurements. Under air conditions, water vapor did not influence the DRIFT spectrum. The most prominent absorption band was at 1,650-1,800 $\mathrm{cm}^{-1}$, which was assigned to a carbonyl group $(\mathrm{C}=\mathrm{O})$ [24]. It should be noted that the carbonyl group peak did not appear under nitrogen conditions. This observation supports that the oxygen plays more dominant role than the water vapor in the formation of $\mathrm{C}=\mathrm{O}$ groups. The large absorption of the carbonyl group also provided firm evidence that the ring cleavage products dominated in the aerosol. The broad spectral band of 3,200-3,700 $\mathrm{cm}^{-1}$ was assigned to water molecules on the surface (stretching vibrations of hydroxyl groups) [25]. This peak was not observed in dry nitrogen. The $\mathrm{C}=\mathrm{C}$ bond in the aromatic 
ring $\left(1,550 \mathrm{~cm}^{-1}\right)$ was not observed under any tested conditions. This result indicates that the ring-cleavage products are the major compounds of the aerosols.

Figure 6. Chemical analysis of aerosol using DRIFT spectrometer; (a) in air (b) in $\mathrm{N}_{2}$. Benzene concentration was about 250 ppmv.

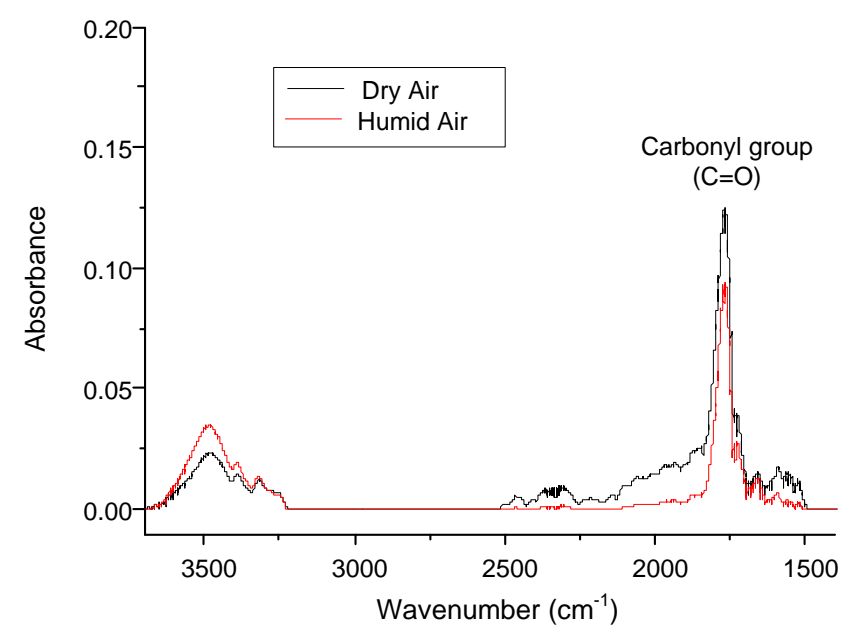

(a) Air

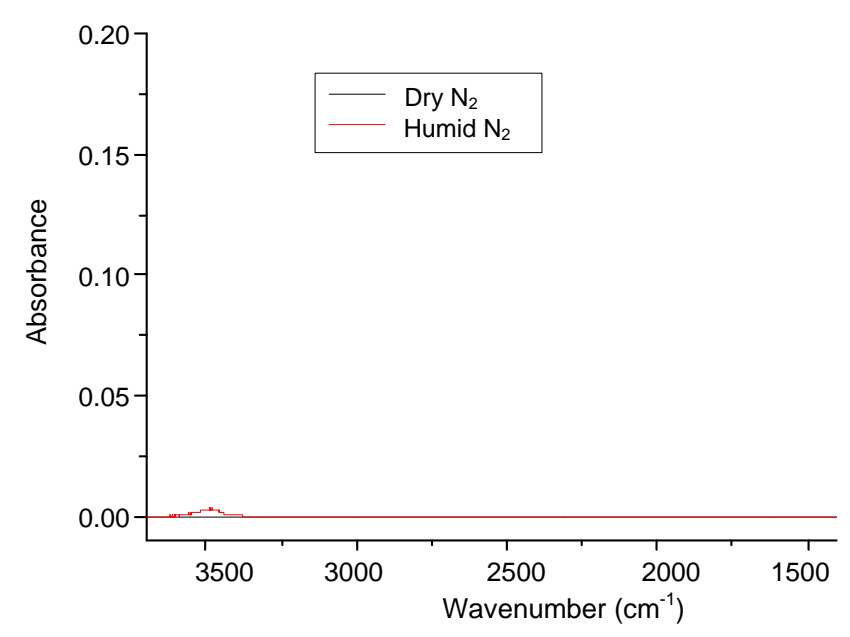

(b) Nitrogen

Electron-beam (e-beam) irradiation of gas mixtures containing VOCs also produces nanometer-sized aerosols [26,27]. Hakoda et al. measured the components of a 50-keV e-beam induced aerosol from $o$-xylene using atmospheric pressure ionization mass spectrometry (API-MS) [28]. The main component in the aerosol were found to be alkyl acids and aldehydes, which are ring-cleavage products. Interestingly, the API-MS signals of $m / z$ 139-203 exhibited a constant interval of $\mathrm{m} / z 16$, which corresponds to atomic oxygen. This result is consistent with the DRIFT spectrum in this study. The formation of carbonyl group and the undetectable levels of aromatic rings suggested that the oxygen species are involved in the ring-cleavage process. Interestingly, the results obtained with NTP or e-beam are quite consistent with those reported in atmospheric chemistry. For example, Forstner et al. studied the formation of SOA from seven aromatic hydrocarbons in $60 \mathrm{~m}^{3}$ outdoor smog chamber experiments and reported the formation unsaturated anhydrides (2,5-furandione, 3-methyl-2,5-furandione, 3-ethyl-2,5-furandione) as the predominant compounds of aerosols [29]. They explained the results using the gas-phase mechanisms involving ring fragmentation. Ring fragmentation reactions were also found to be important in the UV photooxidation of toluene and $o$-xylene [30,31]. Another chamber experiment $\left(9.0\right.$ and $\left.11.3 \mathrm{~m}^{3}\right)$ for the mixture of aromatic VOCs also reported the significant formation of carbonyl groups in SOA [25].

Although differing in concentration, NTP and atmospheric chemistry are based on similar chemical reactions involving CAS such as $\mathrm{OH}$ radicals, $\mathrm{HO}_{2}$ radicals, and $\mathrm{O}_{3}$. Plasma can easily control the concentration of CAS. In this sense, NTP technology can be also used as a tool for the accelerated flow-through testing of gas-to-particle conversion of various VOCs. Preliminary results of this study provided some supporting evidence that the control of aerosol growth is possible by adjusting the energy input to the reactor. 


\section{Conclusions}

Aerosol formation from benzene in a surface discharge nonthermal plasma reactor was investigated using DMA-FC, FE-SEM, and a DRIFT spectrometer. The influences of basic parameters such as specific input energy, inlet concentration, gas composition have been measured and discussed. Since there is a close similarity between atmospheric chemistry and nonthermal plasma chemistry in principle, further information along these lines would be helpful for a better understanding of SOA formation in the atmosphere.

\section{References}

1. Hallquist, M.; Wenger, J.C.; Baltensperger, U.; Rudich, Y.; Simpson, D.; Claeys, M.; Dommen, J.; Donahue, N.M.; George, C.; Goldstein, A.H.; Hamilton, J.F.; Herrmann, H.; Hoffmann, T.; Iinuma, Y.; Jang, M.; Jenkin, M.E.; Jimenez, J.L.; Kiendler-Scharr, A.; Maenhaut, W.; McFiggans, G.; Mentel, T.F.; Monod, A.; Prevot, A.S.H.; Seinfeld, J.H.; Surratt, J.D.; Szmigielski, R.; Wildt, J. The formation, properties and impact of secondary organic aerosol: Current and emerging issues. Atmos. Chem. Phys. 2009, 9, 5155-5236.

2. Kogelschatz, U. Dielectric-barrier discharges: Their history, discharge physics, and industrial applications. Plasma Chem. Plasma Proc. 2003, 23, 1-46.

3. Wagner, H.E.; Brandenburg, R.; Kozlov, K.V.; Sonnenfeld, A.; Michel, P.; Behnke, J.F. The barrier discharge: Basic properties and applications to surface treatment. Vacuum 2003, 71, 417-436.

4. Kim, H.H. Nonthermal plasma processing for air pollution control: A historical review, current issues, and future prospects. Plasma Process. Polym. 2004, 1, 91-110.

5. Kim, H.H.; Ogata, A.; Futamura, S. Atmospheric plasma-driven catalysis for the low temperature decomposition of dilute aromatic compounds. J. Phys. D Appl. Phys. 2005, 38, 1292-1300.

6. Chen, H.L.; Lee, H.M.; Chen, S.H.; Chang, M.B.; Yu, S.J.; Li, S.N. Removal of volatile organic compounds by single-stage and two-stage plasma catalysis systems: A review of the performance enhancement mechanisms, current status, and suitable applications. Environ. Sci. Technol. 2009, 43, 2216-2227.

7. Cocker, D.; Flagan, R.; Seinfeld, J. State-of-the-art chamber facility for studying atmospheric aerosol chemistry. Environ. Sci. Technol. 2001, 35, 2594-2601.

8. Iinuma, Y.; Boge, O.; Gnauk, T.; Herrmann, H. Aerosol-chamber study of the $\alpha$-pinene/O $\mathrm{O}_{3}$ reaction: Influence of particle acidity on aerosol yields and products Atmospheric. Environ. 2004, 38, 761-773.

9. Thomas, C.L.; Egloff, G.; Morrell, J.C. Reactions of hydrocarbons in electrical discharges. Chem. Rev. 1941, 28, 1-70.

10. Paciorek, K.L.; Kratzer, R.H. Electric discharge reactions of hydrocarbons. Can. J. Chem. Eng. 1970, 48, 1777-1779.

11. Anderson, G.K.; Snyder, H.; Coogan, J. Oxidation of styrene in a silent discharge plasma. Plasma Chem. Plasma Proc. 1999, 19, 131-151. 
12. Bubnov, A.G.; Grinevich, V.I.; Aleksandrova, S.N.; Kostrov, V.V. Polymerization of phenol vapor in a barrier-discharge plasma. High Energy Chem. 1997, 31, 264-267.

13. Machala, Z.; Morvova, M.; Marode, E.; Morva, I. Removal of cyclohexanone in transition electric discharges at atmospheric pressure. J. Phys. D Appl. Phys. 2000, 33, 3198-3213.

14. Nolan, P.J.; Kuffel, E. Metal point discharge nuclei and the production of multiply charged ions from condensation nuclei. Geofis. Pur. Appl. 1957, 36, 201-210.

15. Nolan, P.J.; O'Toole, P.J. The condensation nuclei produced by point discharge. Geofis. Pur. Appl. 1959, 42, 117-126.

16. Borra, J.P.; Goldman, A.; Goldman, M.; Boulaud, D. Electrical discharge regimes and aerosol productionin point-to-plane DC high-pressure cold plasmas: Aerosol production by electrical discharges. J. Aerosol. Sci. 1998, 29, 661-674.

17. Borra, J.P. Nucleation and aerosol processing in atmospheric pressure electrical discharges: Powders production, coatings and filtration. J. Phys. D Appl. Phys. 2006, 39, R19-R54.

18. Hidy, G.M. Aerosols Produced by X-Rays; Acamedic Press: New York, NY, USA, 1972; pp. 57-65.

19. Kim, H.H.; Kobara, H.; Ogata, A.; Futamura, S. Comparative assessment of different non-thermal plasma reactors on energy efficiency and aerosol formation from decomposition of gas-phase benzene. IEEE Trans. Ind. Appl. 2005, 41, 206-214.

20. Urashima, K.; Chang, J.S. Removal of volatile organic compounds from air streams and industrial flue gases by non-thermal plasma technology. IEEE Trans. Dielect. Electr. In. 2000, 7, 602-614.

21. Loeb, L.B. Some aspects of breakdown streamers. Phys. Rev. 1954, 94, 227-232.

22. Machala, Z.; Janda, M.; Hensel, K.; Jedlovsky, I.; Lestinska, L.; Foltin, V.; Martisovitsa, V.; Morvova, M. Emission spectroscopy of atmospheric pressure plasmas for bio-medical and environmental applications. J. Mole. Spectroscopy 2007, 243, 230-237.

23. Fomin, O.K. The reactions of active nitorgen with organic molecules. Russ. Chem. Rev. 1967, 36, 725-734.

24. Imanaka, H.; Khare, B.N.; Elsila, J.E.; Bakes, E.L.O.; McKay, C.P.; Cruikshank, D.P.; Sugita, S.; Matsui, T.; Zare, R.N. Laboratory experiments of Titan tholin formed in cold plasma at various pressures: Implications for nitrogen-containing polycyclic aromatic compounds in Titan haze. Icarus 2004, 168, 344-366.

25. Kleindienst, T.E.; Corse, E.W.; Li, W.; Mclver, C.D.; Conver, T.S.; Edney, E.O.; Driscoll, D.J.; Speer, R.E.; Weathers, W.S.; Tejada, S.B. Secondary organic aerosol formation from the irradiation of simulated automobile exhaust. J. Air Waste Manag. Assoc. 2002, 52, 259-272.

26. Hakoda, T.; Kim, H.H.; Okuyama, K.; Kojima, T. Charged nanoparticle formation from humidified gases with and without dilute benzene under electron beam irradiation. J. Aerosol. Sci. 2003, 34, 977-991.

27. Hakoda, T.; Shimada, A.; Kojima, T. Charging processes of particles produced from dilute xylene in air under electron beam irradiation. Radiat. Phys. Chem. 2006, 75, 392-402.

28. Hakoda, T.; Sako, T.; Shimada, A.; Kojima, T. Component analysis of particulate products in electron bean-irradiated xylene/air mixtures using an atmospheric pressure ionization mass spectrometer. Bull. Chem. Soc. Jpn. 2006, 79, 731-737. 
29. Forstner, H.J.L.; Flagan, R.C.; Seinfeld, J.H. Secondary organic aerosol form the photoxidation of aromatic hydrocarbons: Molecular composition. Environ. Sci. Technol. 1997, 31, 1345-1358.

30. Dumdei, B.E.; Kenny, D.V.; Shepson, P.B.; Kleindienst, T.E.; Nero, C.M.; Cupitt, L.T.; Ciaxton, L.D. MS/MS analysis of the products of toluene photooxidation and measurement of their muganenic activity. Environ. Sci. Technol. 1988, 22, 1493-1498.

31. Shepson, P.B.; Edney, E.O.; Corse, E.W. Ring fragmentation reactions on the photooxidations of Toluene and $o$-Xylene. J. Phys. Chem. 1984, 88, 4122-4126.

(C) 2011 by the authors; licensee MDPI, Basel, Switzerland. This article is an open access article distributed under the terms and conditions of the Creative Commons Attribution license (http://creativecommons.org/licenses/by/3.0/). 